\title{
Tekrarlı yaya yürüyüşü ve kısa süreli kinematik GPS+GLONASS gözlemleriyle PPP yönteminin performans analizi
}

\author{
Nursu Tunalıoğlu ${ }^{1 *}(\mathbb{D}$ \\ ${ }^{1}$ Yıldız Teknik Üniversitesi, Davutpaşa Kampüsü, Inşaat Fakültesi, Harita Mühendisliği Bölümü, Esenler, İstanbul, Türkiye.
}

\begin{abstract}
Öz: Küresel Konum Belirleme ve Uydu Sistemleri (Global Navigation Satellite Systems, GNSS) tabanl konum belirleme uygulamalarında Hassas Nokta Konum Belirleme (Precise Point Positioning-PPP) yönteminin etkinliği ve kullanımı bă̆ll konum belirlemeye göre giderek artmaktadır. Buna karşın farklı platformlarda gerçekleştirilen statik ve kinematik moddaki birçok çalı̧̧mada geleneksel standart PPP yöntemi için en büyük dezavantaj taşıyıcı faz gözlemleri için yakınsama süresinin uzun olmasıdır. Bu nedenle PPP'ye dayalı statik ve kinematik moddaki çalışmalarda gözlem süresi sıklıkla uzun tutulmaktadır. Gerçekleştirilen bu çalışmada PPP'de gözlem süresine ve dolayısıla tamsay belirsizliği çözümüne bağll olarak elde edilen konum doğruluğu dikkate alınarak, tekrarlı ve kısa süreli yaya yürüyüşleriyle elde edilen kinematik GPS+GLONASS gözlemlerinin PPP konum belirleme performansı kısa, orta ve uzun bazlar için bağıl konum belirleme çözümleriyle karşılaş̧ııılmıştır. Karşılaştırma için dünya genelinde yaygın olarak kullanılan ve taşıyıcı faz gözlemleri için yakınsama süresinin kısaltılması için yeni algoritmik yaklaşımlar kullanan internet tabanlı GNSS veri değerlendirme servisi CSRSPPP tercih edilmiştir. Sonuçlar PPP yönteminin kısa süreli kinematik gözlemler için de bağıl çözümlere eşdeğer sayılacak yüksek doğrulukta konum bilgisinin elde edilmesinde etkin olarak kullanılabileceğini açıkça ortaya koymaktadır.
\end{abstract}

Anahtar Sözcükler: Hassas nokta konum belirleme, Kinematik konum belirleme, GPS+GLONASS, Kısa gözlem süresi

\section{Performance analysis of PPP method with repeatedly pedestrian walk and short-time kinematic GPS+GLONASS observations}

\begin{abstract}
In Global Navigation Satellite Systems (GNSS)- based positioning applications, the efficiency and use of Precise Point Positioning (PPP) technique have gradually increased compared to the relative positioning technique. However, in many studies performed on different platforms in static and kinematic modes, the largest disadvantage for the traditional standard PPP method is the long convergence time for carrier phase observations. Therefore, observation duration in studies that are based on the PPP method in static and kinematic modes is often kept long. In this study, considering the positioning accuracy obtained depending on observation duration and ambiguity resolution in PPP, the performance of kinematic GPS + GLONASS observations obtained by repeated and short pedestrian walks were compared with relative positioning solutions for short, medium and long bases. For comparison, the internet-based GNSS data processing service namely CSRS-PPP, which is widely used worldwide and uses new algorithmic approaches to shorten the convergence time for carrier-phase observations, was preferred. The results clearly demonstrate that the PPP method for short-term kinematic observations can be used effectively for obtaining high-accurate positioning information, which is also equivalent to relative solutions.
\end{abstract}

Keywords: Precise point positioning, Kinematic positioning, GPS+GLONASS, Short observation duration 


\section{Giriş}

Hassas Nokta Konum Belirleme (Precise Point Positioning, PPP) yöntemi, 1990'ların sonunda bağıl konum belirleme tekniğine alternatif olarak geliştirilmiş, tek bir Küresel Konum Belirleme ve Uydu Sistemleri (Global Navigation Satellite Systems, GNSS) alıcısının kullanıldığı özel bir mutlak konum belirleme tekniğidir (Zumberge, Heflin, Jefferson, Watkins \& Webb, 1997). GNSS gözlemleri için çift frekanslı iyonosfer-bağımsız doğrusal (lineer) kombinasyonun kullanımı temel olarak geleneksel standart PPP'yi tanımlamaktadır (Chen \& Gao, 2005; Héroux vd., 2004; Zumberge vd., 1997). PPP yöntemi küresel ölçekte, statik ve kinematik modda cm-dm seviyesinde doğruluk sağladığından büyük ilgi görmüş ve yaygın olarak kullanılmaya başlanmıştır. Özellikle CSRS-PPP, GAPS, APPS, MagicGNSS-PPP ve Trimble Center-Point RTX gibi internet (web) tabanlı online GNSS veri değerlendirme servislerinin gelişimiyle beraber ölçü sonrası değerlendirme (post-processing) için PPP yöntemi yaygın kullanıma sahip olmuştur (Öcalan, Erdoğan, Tunalığlu \& Durdağ, 2016). Ardından International GNSS Service (IGS) başta olmak üzere Bundesamt für Kartographie und Geodäsie (BKG), Centre National D’Etudes Spatiales (CNES), German Research Centre for Geosciences (GFZ), European Space Agency (ESA) gibi sivil organizasyonların RTCM veri formatı ve NTRIP protokolü üzerinden ücretsiz olarak sağladıkları gerçek zamanlı hassas uydu yörünge ve saat düzeltme bilgileriyle, PPP yönteminin gerçek zamanlı (real-time) uygulamalarında da büyük bir artış olmuştur (Erdoğan, Karlıtepe, Öcalan \& Tunalıŏlu, 2018). Bu nedenle GNSS tabanlı hassas konum belirlemede, jeodezikjeofizik çalışmalar, iklimbilim ve atmosferik araştırmalar, hidrografik-oşinografik ölçmeler, deformasyonların izlenmesi, tarım, madencilik, inşaat ve enerji alanı uygulamaları gibi pek çok alanda PPP yöntemi yaygın olarak kullanılmaktadır (Erdoğan vd., 2018; Lipatnikov \& Shevchuk, 2019). Yakın bir gelecekte ise özellikle araç park etme, kargo teslimatı, ortak araç kullanımı, acil durum müdahalesi ve otonom sürüş gibi akıllı şehir mobil servis uygulamalarında da etkin olarak kullanımı beklenmektedir (Robustelli, Baiocchi \& Pugliano, 2019).

PPP yönteminin gerek ölçü sonrası değerlendirme, gerekse gerçek zamanlı konum belirleme için sağladığı birçok avantaj bulunmaktadır. Tek bir GNSS alıcısının kullanılması, maliyetin görece düşük olması, referans bir istasyona/istasyonlara gereksinim duyulmaması ve dolayısıyla ek bir veriye ihtiyaç duyulmadan hassas konum bilgisini mutlak olarak kullanıcıya sağlayabilmesi bunların başlıcalarıdır. Bu yönüyle maliyet, işgücü ve konum doğruluğu kriterleri açısından bağıl konum belirleme tekniğine önemli bir alternatif oluşturmaktadır (Erdoğan vd., 2018; Öcalan vd., 2016). PPP yönteminde, başta hassas uydu yörünge ve saat bilgileri olmak üzere, kod ve taşıyıcı faz gözlemlerine ait sinyal kayıklık (bias) bilgileri, iyonosferik ve troposferik gecikmeler ve diğer özel hatalar (katı yeryuvarı gelgiti, okyanus yüklemesi, alıcı ve uydu anteni faz dönmesi vd.) ve modellemeler düzeltme olarak kullanılmaktadır. PPP için bu düzeltmeler genel olarak Durum Uzay Temsili (State Space Representation, SSR) parametreleri olarak adlandırılmaktadır. Bu bağlamda gerek ölçü sonrası değerlendirme ile PPP, gerekse gerçek zamanlı PPP uygulamalarında, sivil organizasyonlar ya da ticari kuruluşların internet ve/veya haberleşme uydu linklerinden sağladıkları SSR düzeltme parametreleri kullanılmaktadır (Wübbena, Schmitz \& Bagge, 2005).

Geleneksel PPP'de taşıyıcı faz tamsayı belirsizliği çözümü (carrier-phase ambiguity resolution) için gerekli olan yakınsama süresinin bağıl konum belirlemeye göre çok daha uzun olması, tekniğin en büyük dezavantajı olarak görülmektedir. Bu süre uydu dizilişine ve veri kalitesine göre değişkenlik göstermekle birlikte, 30 dakika ile saatler arasında zaman alabilmektedir (Bisnath \& Gao, 2008). Bu nedenle geleneksel PPP yöntemi ile gerçekleştirilen çalışmalarda ölçü süresinin uzun olması tercih edilmektedir. Bu dezavantajın giderilmesi yönünde pek çok araştırma yapılmış, süreç içerisinde yakınsama süresinin kısaltılmasına ve dolayısıyla ölçü süresinin azalmasına katkı sağlayacak PPP with Ambiguity Resolution (PPP-AR) olarak adlandırılan algoritmik yaklaşım geliştirilmiştir (Bezcioğlu, Yiğit \& Bodur, 2019; Li, Ge, Zhang \& Wickert, 2013). 
PPP uygulamalarında dünya genelinde sıklıkla kullanılan CSRS-PPP servisi, geleneksel PPP uygulamalarında taşıyıı faz belirsizliğinin çözümünde yakınsama süresinin kısaltılmasına katkı sağlayan PPP-AR yönteminin gelişim dinamiğini dikkate alarak bu yönde servis yazılımını geliştirmektedir. CSRS-PPP servisi, sistemin sürekli iyileștirilmesi ve geliştirilmesi adına modernize edilmektedir. Servisin önemli bir dönüşümü yazılım altyapısının 2018 yılında "GPSPACE v1.05_11216" dan "SPARK v2.11.0" geçmesiyle olmuştur. SPARK yazılımının en önemli özelliği geleneksel PPP'den PPP-AR algoritmasına geçiş için belli ön deneysel algoritmaları içermesidir. PPP-AR'a geçiş için bir ön arayüz olan SPARK sürümü ile taşıyıcı faz belirsizliği çözümü için daha hızlı yakınsama sağlaması ve böylece daha kısa ölçü süreleri ile yüksek konum doğruluğunun sağlanması amaçlanmıştır. NRCan tarafından yapılan deneylerde SPARK yazılımıyla kinematik çözümlerde \%20-30 oranında gelişme, yükseklik belirlemede 4-5 mm arasında iyileşme sağlandığı tespit edilmiştir. Böylece CSRS-PPP’nin yeni SPARK yazılım sürümüyle, daha etkin PPP çözümlerinin gerçekleştirilmesi, ilerleyen süreçte de yapılan güncellemelerle birlikte geleneksel standart PPP algoritmasından, yani faz başlangıç belirsizliğinin tam sayı değil kesirli bir sayı olarak kestirilmesinden, PPP-AR algoritmasına, yani faz başlangıç belirsizliğinin tam sayı olarak kestirilmesine geçiş hedeflenmiştir (URL-1).

Bu gelişim dinamiği dikkate alınarak gerçekleştirilen bu çalışmada, Yıldız Teknik Üniversitesi (YTÜ) Davutpaşa Kampüsü spor sahasında kinematik bir test gerçekleştirilmiştir. $1 \mathrm{~Hz}$ veri kayıt aralığıyla tekrarlı yaya yürüyüşü ve kısa süreli kinematik GPS+GLONASS gözlemleriyle veri toplanmıştır. Elde edilen GPS+GLONASS gözlemleri hem farklı baz uzunluklarına sahip bağıl konum belirleme çözümleriyle değerlendirilmiş, hem de CSRS-PPP online veri değerlendirme servisinin SPARK sürümüyle değerlendirilmiştir. Böylece PPP yönteminin performansı, tekrarlı ve kısa süreli kinematik GPS+GLONASS gözlemleri kullanılarak test edilmiş, farklı baz uzunluklarındaki bağıl konum belirleme çözümleriyle karşılaştırılarak incelenmiştir.

\section{Geleneksel PPP ve PPP-AR Yaklaşımları}

Geleneksel PPP'de temel olarak SSR düzeltme parametrelerinden hassas uydu yörünge ve saat ürünleri kullanılmaktadır. PPP-AR modelinde ise hassas uydu yörünge ve saat düzeltme ürünlerine ek olarak kod ve taşıyıcı faz sinyal kayıklık (bias) düzeltme bilgileri kullanılmaktadır. PPP-AR yaklaşımında SSR düzeltme parametrelerinin kullanımında özellikle taşıyıcı faz sinyal kayıklık (phase biases) düzeltme bilgilerinin kullanımı önemlidir. Bu unsur taşıyıcı faz tamsayı belirsizliği çözümü için gerekli olan yakınsama süresinin kısaltılmasında da belirleyicidir. Bu yaklaşımların gerçek zamanlı uygulamalarda adlandırılması yaygın kullanımıyla Real-Time PPP (RT-PPP) şeklindedir. Gerçek zamanlı uygulamalar açısından, tamsayı belirsizliğinin kısa sürede çözüldüğü ve SSR düzeltme parametrelerinden hassas uydu yörünge ve saat, kod ve taşıyıcı faz sinyal kayıklığı (bias) ile iyonosferik ve troposferik gecikme düzeltme ürünlerinin kullanıldığı yaklaşım ise PPP-RTK olarak adlandırılmaktadır (Choy \& Harima, 2019). Geleneksel PPP, PPP-AR ve PPP-RTK yaklaşımlarının SSR düzeltme ürünleri, yakınsama zamanı ve yatay doğruluk açısından karşılaşıırmaları Tablo 1'de verilmektedir.

Kara, hava ve deniz gibi farklı platformlardaki kinematik GNSS gözlemleriyle gerçekleştirilen uygulamalarda, geleneksel PPP'nin sağladığı konum doğruluğu ve duyarlılık açısından yapılan birçok araştırma bulunmaktadır. Alkan, Saka, Ozulu ve İlçi (2017), kısıtlı uydu görüşü olması durumunda kinematik geleneksel PPP yönteminin performansını yalnızca GPS ve GPS+GLONASS kombinasyon çözümleriyle karşılaştırarak incelemişler, GLONASS uydularının çözüme olan katkısını vurgulamışlardır. Alkan ve Öcalan (2013), yüksek maliyetli jeodezik alıcı ile düşük maliyetli Original Equipment Manufacturer (OEM) alıcıyı deniz platformunda teknede kullanarak eş zamanlı ölçme çalışması gerçekleştirmiş, kinematik geleneksel PPP yönteminin performansını bağıl yöntemden elde edilen sonuçlar ile karşılaştırmışlardır. Geng, Teferle, Meng ve Dodson (2010), uzak deniz platformlarında kinematik geleneksel PPP yönteminin performansını kısa ve uzun süreli 
gözlemler yönünden incelemişler, uzun süreli gözlemlerin doğruluk açısından getirdiği katkıyı belirtmişlerdir. Bezcioğlu vd. (2019), Antarktika'da deniz platformunda botla gerçekleştirdikleri çalışmada, PPP-AR ve geleneksel PPP tekniklerinin performansını, bağıl konum belirleme çözümleri ile karşılaştırmış, PPP-AR yönteminin çözüme katkısını ortaya koymuşlardır. Grayson, Penna, Mills ve Grant (2018) insansız hava aracı (IHA) ile gerçekleştirdikleri 25-30 dakikalık uçuş sonrasında İHA-fotogrametrisi için elde edilecek ürünlerde uçuş kinematik GPS verilerini geleneksel PPP ve bağıl konum belirleme teknikleri ile değerlendirmiş, fotogrametrik haritalama için PPP’nin yatayda $\mathrm{cm}$ doğruluk sağladığını ortaya koymuşlardır. Gross, Watson, D'Urso ve Gu (2016) çalışmalarında 5 dakika ve daha kısa süreli İHA uçuşlarından elde edilen kinematik GPS verilerini farklı PPP analiz yöntemleri ile değerlendirmiş, sonuçta $\mathrm{cm}$-dm mertebesindeki doğruluklarla referans diferansiyel çözümlere yakınsadığını belirtmişlerdir. Farklı platformlarda gerçekleştirilen kinematik PPP uygulamalarının yanında $1 \mathrm{~Hz}$ ve daha yüksek frekanslı GNSS verileriyle kinematik geleneksel PPP'nin performansının araştırıldığı yapı sağlığının izlenmesi, tektonik çalışmalar, heyelanların izlenmesi vb. gibi deformasyonların izlenmesine yönelik araştırmalar da bulunmaktadır (Xu vd., 2013; Yiğit, 2016).

Tablo 1: Geleneksel PPP, PPP-AR, PPP-RTK yaklaşımlarının karşılaştırması (Choy \& Harima, 2019)

\begin{tabular}{|c|c|c|c|}
\hline Yöntem & SSR düzeltme ürünleri & Yakınsama zamanı & Yatay doğruluk \\
\hline Geleneksel PPP & $\begin{array}{c}\text { Uydu yörüngeleri } \\
\text { Uydu saatleri }\end{array}$ & $\begin{array}{c}>40 \text { dakika } \\
\text { (k1smi/float çözümler) }\end{array}$ & $\mathrm{cm}$ \\
\hline PPP-AR & $\begin{array}{c}\text { Uydu yörüngeleri } \\
\text { Uydu saatleri } \\
\text { Kod sinyal kayıklığı (code biases) } \\
\text { Taşıyıcı faz sinyal kayıklığı (phase biases) }\end{array}$ & 30 dakika & $\mathrm{cm}$ \\
\hline PPP-RTK & $\begin{array}{c}\text { Uydu yörüngeleri } \\
\text { Uydu saatleri } \\
\text { Kod sinyal kayıklığı (code biases) } \\
\text { Taşıyıcı faz sinyal kayıklığı (phase biases) } \\
\text { İyonosferik gecikme } \\
\text { Troposferik gecikme } \\
\end{array}$ & $<1$ dakika & $\mathrm{cm}$ \\
\hline
\end{tabular}

$\mathrm{Bu}$ çalışmada yukarıda belirtilen çalışmalardan farklı olarak standart ölçülere sahip bir spor sahasında, aynı güzergâh izi üzerinde tekrarlı yaya yürüyüşü ve kısa süreli GPS+GLONASS gözlemleriyle kinematik bir test yapılmıştır. Her bir tam tur yürüyüş süresi ortalama 6 dakika olacak biçimde, 4 tam tur tekrarlı yürüyüş yapılmış, elde edilen $1 \mathrm{~Hz}$ verilerin PPP performansı farklı bağıl konum belirleme çözümleri ile karşılaştırılmıştır. Böylece ölçü süresinin kısaltılması durumunda PPP yöntemi ile kinematik uygulamalarda elde edilecek yatay ve düşey konum doğruluklarındaki performans tekrarlıl1k analizi ile vurgulanmıştır.

\section{Uygulama}

\subsection{Kinematik Test}

Tekrarlı yaya yürüyüşü ve kısa süreli kinematik GPS+GLONASS gözlemleriyle PPP yönteminin performans analizi için YTÜ Davutpaşa Kampüsü'nde bulunan spor sahası çalışma bölgesi olarak seçilmiştir. Çalışmada iki adet Topcon Hiper-SR GNSS alıcısı kullanılmıştır. Topcon Hiper-SR, Fence anten yapısııı kullanan, GPS ve GLONASS uydularına ait L1+L2+L2C frekanslarında sinyal alabilen jeodezik nitelikte bir alıcıdır. Uygulama için alıcılardan biri bağıl konum belirleme ile elde edilecek referans koordinat çözümleri için YTÜ İnşaat Fakültesi çatısında yer alan ERBD noktasına statik modda kurulmuştur. Kısa süreli tekrarlı test yürüyüşü için kullanılacak kinematik moddaki diğer alıcı ise yürüyüş yapan kişinin sırt çantasına jalonla düşeyde sabitlenerek bağlanmıştır (Şekil 1). Sabit referans alıcısının bulunduğu ERBD noktası ile kinematik testin yapıldığı spor sahası arasındaki ortalama baz uzunluğu 240 m'dir (Şekil 2). Kinematik testin yapıldığı spor sahasında 
yaya yürüyüşü, koşu platformunun en diş kulvarındaki çizgi üzerinde gerçekleştirilerek GNSS gözlemlerinin aynı güzergâhtaki iz üzerinde tekrarlılığı sağlanmıştır.

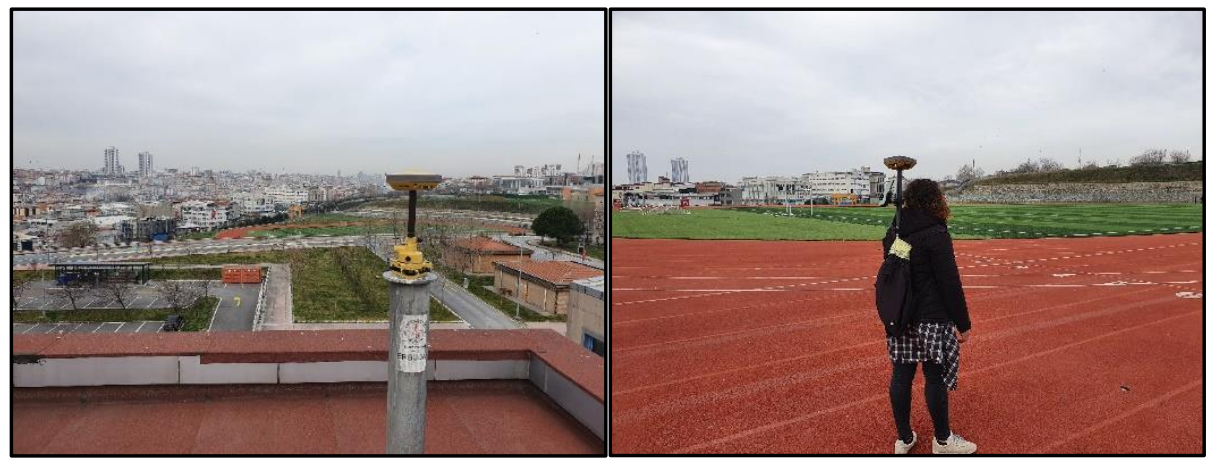

Şekil 1: Sabit ve hareketli GNSS alıcıları

4 Mart 2020 (ölçü epoğu: 2020.1753) tarihinde gerçekleştirilen uygulamada GPS+GLONASS gözlemleri 1 saniye veri kayıt aralığı ve $10^{\circ}$ yükseklik açısı ile eş zamanlı olarak elde edilmiştir. Spor sahası koşu pistinin en dış kulvarındaki başlangıç noktası dikkate alınarak, aynı güzergâh iz çizgisi üzerinde aynı tempo ve hızla 4 tam tur tekrarlı yürüyüş gerçekleştirilmiştir. Dört tam tur için tekrarlı kinematik test yürüyüş süresi 24 dakika 36 saniye sürmüştür. Sabit GNSS alıcısının bulunduğu ERBD noktasında ise 5 saat statik GNSS gözlem verisi elde edilmiştir.

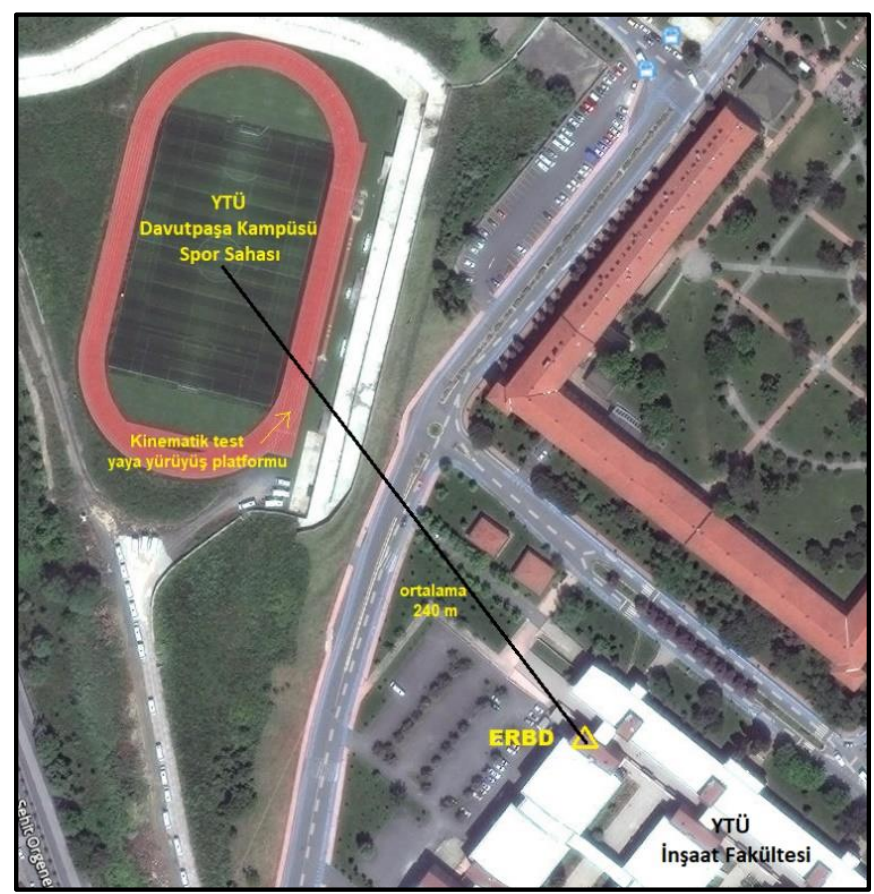

Şekil 2: Çalışma bölgesi

\subsection{Verilerin Değerlendirilme Stratejisi}

PPP yönteminin ölçü sonrası değerlendirme için yaygın kullanımında etkili olan CSRS-PPP, GAPS, APPS, MagicGNSSPPP ve Trimble Center-Point RTX gibi internet (web) tabanlı online GNSS veri değerlendirme servisleri bulunmaktadır. Bu servisler içerisinde NRCan tarafından geliştirilen ve 2003 yılından bu yana hizmet veren CSRS-PPP servisi, L1 (tek frekans) ve L1+L2 (çift frekans) sinyallerini, yalnızca GPS veya GPS+GLONASS gözlemlerini statik ya da kinematik modda değerlendirebilen, hızlı çözüm sağlayan efektif yapıya sahip bir servis olarak ön plana çıkmaktadır. International Terrestrial Reference Frame (ITRF) ve North American Datum of 1983 (NAD83) datumlarında koordinat bilgisi üreten CSRS-PPP servisi, $1 \mathrm{~Hz}$ ve daha yüksek frekanslı verileri çözme yeteneğine sahiptir. PPP çözümlerinde ölçü epoğunu dikkate alarak IGS ve NRCan tarafından sağlanan en yüksek doğruluğa sahip uydu yörünge ve saat ürünlerini kullanmaktadır. Faz kesikliği 
filtrelemesi, uydu ve alıcı anteni faz merkezi kayıklığının giderilmesi, referans datum dönüşümü ve okyanus yüklemesi etkisinin giderilmesi gibi düzeltmeleri de içermektedir (Bezcioğlu vd., 2019; El-Mowafy, 2011; URL-1). CSRS-PPP servisi, SPARK yazılımıyla ön deneysel olarak PPP-AR algoritmasına geçiş için hazırlık yapmaktadır. Servisin PPP-AR algoritmasını kullanımında SPARK bir araç olarak sunulmaktadır. CSRS-PPP servisinin 2020 yılında tam olarak PPP-AR algoritmalarını kullanan yeni yazılım sürümünün hizmet vermesi beklenmektedir (URL-1).

Gerçekleştirilen bu çalışmada 24 dakika 36 saniye süren kısa süreli ve tekrarlı kinematik GPS+GLONASS gözlemleri CSRSPPP ile değerlendirilerek analiz edilmiştir. Elde edilen ITRF2014 datumu ve ölçü epoğundaki PPP sonuçlarının doğruluğunu epok-epok analiz etmek için referans alınan bağıl konum belirleme çözümleri ise Topcon Magnet Tools programı kullanılarak GPS+GLONASS uydu kombinasyonu çözümleriyle karşılaştırılmıştır. Tüm bağıl konum belirleme çözümlerinde IGS tarafından yayınlanan hassas uydu yörünge (final) dosyaları kullanılmıştır.

Çalışmada bağıl konum belirleme çözüm stratejisi için üç farklı yaklaşım kullanılmıştır. Kısa, orta ve uzun baz çözümlerinin ölçü süresinin azaltıldığı kinematik GPS+GLONASS gözlemlerine olan etkisinin de incelenmesi için çalışma bölgesine en yakın ERBD noktası (ortalama baz uzunluğu $240 \mathrm{~m}$ ), ISTN noktası (ortalama baz uzunluğu 6 km) ve ISTA noktasına (ortalama baz uzunluğu $14 \mathrm{~km}$ ) dayalı olarak bağıl çözümler elde edilmiştir. Bağıl konum belirleme çözümlerinde referans alınan tüm sabit noktaların (ERBD, ISTN, ISTA) konumları ITRF2014 datumunda ve ölçü epoğunda (2020.1753) hesaplanmıştır. Böylece CSRS-PPP ile epok-epok elde edilen kinematik PPP çözümleri daha sonra referans ERBD noktasına dayalı bağıl çözümler, TUSAGA-Aktif ağına ait ISTN referans istasyonu ile uluslararası IGS ağına ait ISTA referans istasyonu noktalarına dayalı olarak yapılan bağıl çözümlerle karşılaştırılmıştır. Karşılaştırmaların tamamı ITRF2014 datumu ölçü epoğunda ve GRS80 elipsoidi kullanılarak elde edilen $3^{\circ}$ dilim genişliği, $30^{\circ}$ dilim orta meridyeni TM projeksiyon koordinatları (x, y) ile elipsoidal yüksekliğe (h) göre yapılmıştır.

\subsection{Bulgular}

Çalışmada kullanılan spor sahası koşu pistinde en dış kulvara ait çizgi üzerinde yaklaşık yaya yürüyüş hızına $(\sim 1.5 \mathrm{~m} / \mathrm{s})$ yakın bir hızla gidilerek toplam 24 dakika 36 saniye süren ölçü süresi esnasında 4 tam tur için (her bir tur ortalama $6 \mathrm{dk}$.) tekrarlı kinematik GPS+GLONASS gözlemleri elde edilmiştir. Her turda başlangıç noktası göz önüne alınıp alt veri gruplarına ayrılarak değerlendirmeler bu veri grupları için ayrı ayrı yapılmıştır. Analizlerde kısa (ERBD), orta (ISTN), uzun (ISTA) baz olmak üzere 3 farklı bağıl çözümleme değeri elde edilmiştir. Üç farklı bağıl çözüm için elde edilen epok-epok koordinat değerlerinin, yaya yürüyüşü ile elde edilen kinematik PPP çözümlerinden farkları alınarak $\Delta \mathrm{x}, \Delta \mathrm{y}, \Delta \mathrm{h}$ koordinat fark bileşenleri elde edilmiştir.

Yaya yürüyüş hızında $(\sim 1.5 \mathrm{~m} / \mathrm{sn})$ toplanan kinematik verilerin PPP yöntemi ile elde edilen koordinat değerlerinden kısa baz bağıl çözümlerinin çıkarılmasıyla elde edilen farklar Şekil 3’te gösterilmektedir. Bununla birlikte elde edilen koordinat farklarına ait istatistiksel bilgiler minimum ve maksimum karesel ortalama hata $(\mathrm{KOH})$ değerleri koyu renkte belirtilerek Tablo 2'de sunulmuştur. Koordinat farklarına ait istatistiksel analizlerde ortalama, minimum ve maksimum değerler, aralık değer, $\mathrm{KOH}$ ve ortalama mutlak hata $(\mathrm{OMH})$ değerleri göz önüne alınmıştır. Şekil 3 incelendiğinde, $\Delta y$ bileşenine ait farkların $\Delta \mathrm{h}$ bileşenine göre sıfırdan daha uzak olmasına rağmen aralık değerinin daha az olduğu yani daha stabil bir farka sahip olduğu görülmektedir. Kısa baz bağıl çözüme göre alınan farklarda, $\Delta \mathrm{x}, \Delta \mathrm{y}$ ve $\Delta$ h değerlerine ait $\mathrm{KOH}$ değerleri sırasıyla \pm 0.0193 $\mathrm{m}$ ile $\pm 0.0259 \mathrm{~m} ; \pm 0.0906 \mathrm{~m}$ ile $\pm 0.0962 \mathrm{~m} ; \pm 0.0532 \mathrm{~m}$ ile $\pm 0.0692 \mathrm{~m}$ aralıklarında elde edilmiştir. Dört tur için oluşan altı kombinasyona bakıldığında yatay koordinat bileşenleri için $\mathrm{KOH}$ farkları $\mathrm{mm}$ seviyesinde kalırken, $\Delta \mathrm{h}$ bileşeninde $\mathrm{cm}$ seviyesinde $\left(\Delta \mathrm{x}_{\text {maks }}=0.0066 \mathrm{~m}\right.$ ve $\Delta \mathrm{x}_{\min }=0.0002 \mathrm{~m} ; \Delta \mathrm{y}_{\mathrm{maks}}=0.0056 \mathrm{~m}$ ve $\Delta \mathrm{y}_{\min }=0.0011 \mathrm{~m} ; \Delta \mathrm{h}_{\text {maks }}=0.0160 \mathrm{~m}$ ve $\Delta \mathrm{h}_{\text {min }}=$ $0.0005 \mathrm{~m}$ ) olduğu görülmüştür. Bununla birlikte, farkların mutlak değerlerine bağlı hesaplanan $\mathrm{OMH}$ değerlerinin $\mathrm{KOH}$ 
değerlerine göre her turda ve her bileşen için bir miktar düştüğü görülmektedir.

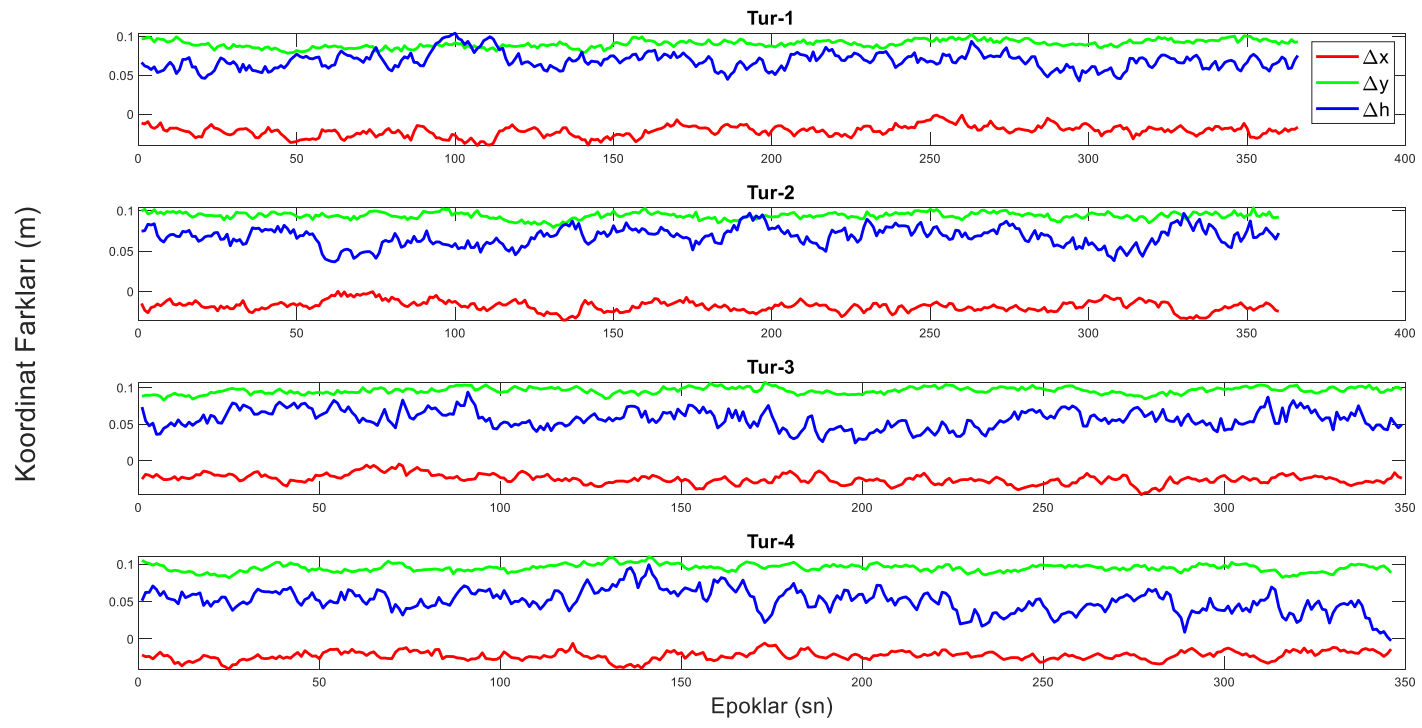

Şekil 3: PPP ile kısa baz (ERBD) bağıl çözüm koordinat farkları

Tablo 2: PPP ile kısa baz (ERBD) bağıl çözüm arasındaki farklara ait istatistiksel sonuçlar

\begin{tabular}{|c|c|c|c|c|c|c|}
\hline & \multicolumn{3}{|c|}{ TUR-1 } & \multicolumn{3}{|c|}{ TUR-2 } \\
\hline & $\Delta \mathbf{x}(\mathbf{m})$ & $\Delta y(m)$ & $\Delta h(m)$ & $\Delta \mathbf{x}(\mathbf{m})$ & $\Delta y(m)$ & $\Delta h(\mathrm{~m})$ \\
\hline Ortalama & -0.0218 & 0.0904 & 0.0684 & -0.0181 & 0.0939 & 0.0677 \\
\hline Minimum & -0.0406 & 0.0783 & 0.0426 & -0.0355 & 0.0792 & 0.0366 \\
\hline Maksimum & -0.0013 & 0.1028 & 0.1040 & 0.0002 & 0.1036 & 0.0970 \\
\hline Aralık & 0.0393 & 0.0245 & 0.0614 & 0.0357 & 0.0244 & 0.0604 \\
\hline $\mathrm{KOH}$ & 0.0229 & 0.0906 & 0.0692 & 0.0193 & 0.0940 & 0.0687 \\
\hline \multirow[t]{3}{*}{$\mathrm{OMH}$} & 0.0218 & 0.0904 & 0.0684 & 0.0181 & 0.0939 & 0.0677 \\
\hline & \multicolumn{3}{|c|}{ TUR-3 } & \multicolumn{3}{|c|}{ TUR-4 } \\
\hline & $\Delta x(m)$ & $\Delta y(m)$ & $\Delta \mathrm{h}(\mathrm{m})$ & $\Delta x(m)$ & $\Delta y(m)$ & $\Delta \mathrm{h}(\mathrm{m})$ \\
\hline Ortalama & -0.0250 & 0.0961 & 0.0570 & -0.0224 & 0.0950 & 0.0509 \\
\hline Minimum & -0.0463 & 0.0828 & 0.0243 & -0.0404 & 0.0816 & -0.0025 \\
\hline Maksimum & -0.0045 & 0.1073 & 0.0938 & -0.0057 & 0.1098 & 0.0992 \\
\hline Aralık & 0.0418 & 0.0245 & 0.0695 & 0.0347 & 0.0282 & 0.1017 \\
\hline $\mathrm{KOH}$ & 0.0259 & 0.0962 & 0.0584 & 0.0231 & 0.0951 & 0.0532 \\
\hline $\mathrm{OMH}$ & 0.0250 & 0.0961 & 0.0570 & 0.0224 & 0.0950 & 0.0509 \\
\hline
\end{tabular}

Ayrıca koordinat bileşenlerine ait farkların dağılım grafikleri de çizilmiştir. Şekil 4’te gösterilen kırmızı çizgi, her bir dağılım grafiğine uyan Gauss normal dağılım eğrisini ifade etmektedir. Buna göre $\Delta \mathrm{x}$ değerleri her turda, $\Delta \mathrm{y}$ ve $\Delta \mathrm{h}$ koordinat fark bileşenlerinden daha fazla sıfıra yakınsamıştır.

Toplanan kinematik verilerin PPP yöntemi ile elde edilen koordinat değerleri ile orta baz (ISTN) bağıl çözümden olan farkları Şekil 5'te verilmiştir. Bu çözüme ait elde edilen koordinat farklarının istatistiksel bilgileri ise minimum ve maksimum KOH değerleri koyu renkte belirtilerek Tablo 3'te sunulmuştur. Şekil 5'te, $\Delta$ y değerlerinin sıfıra yakınsamasının $\Delta$ h değerlerine göre daha fazla olduğu görülmektedir. Aynı zamanda, $\Delta y$ farklarının aralık değeri de ERBD bağıl çözümüne benzer şekilde bulunmuştur. 

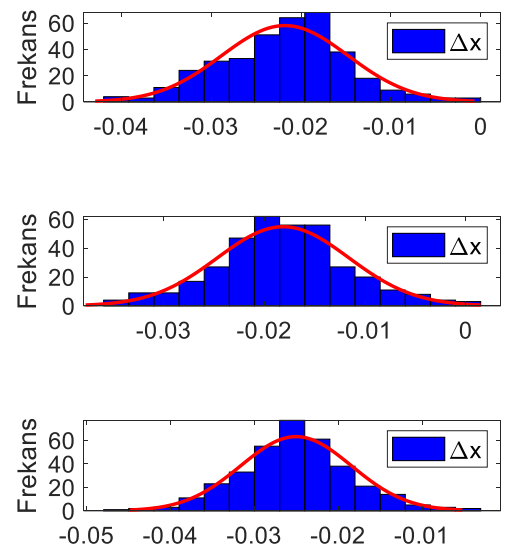

(m)

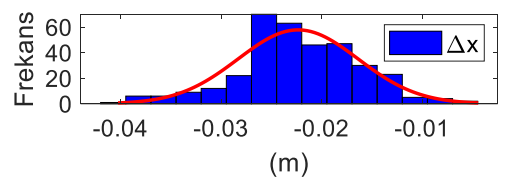

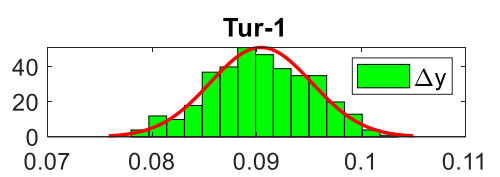
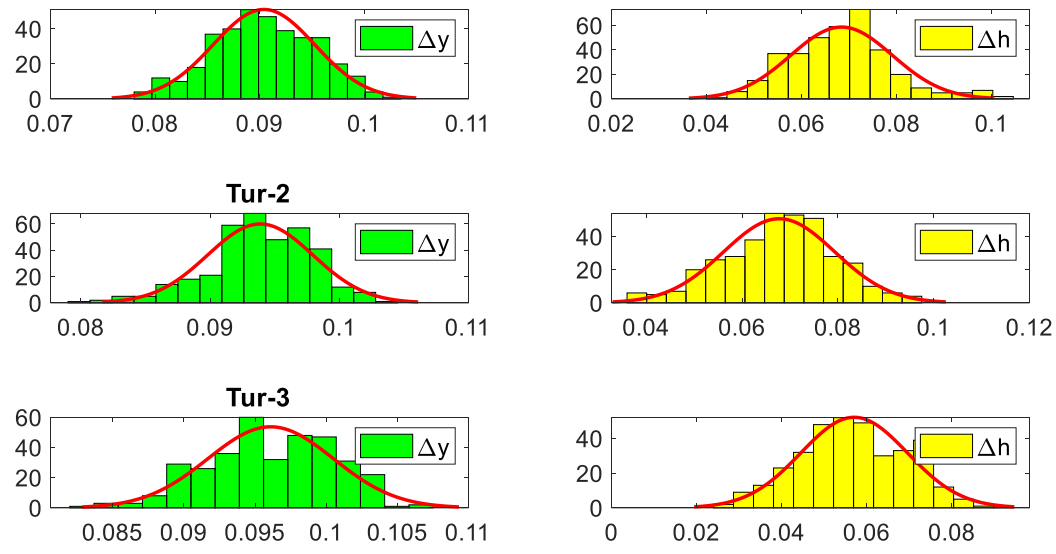

$(\mathrm{m})$

Tur-4

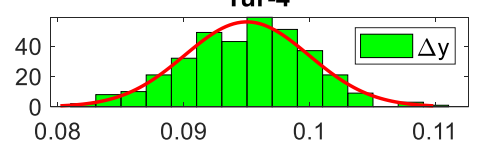

$(\mathrm{m})$

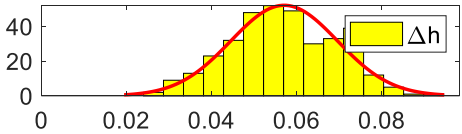

(m)

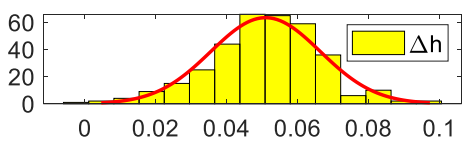

$(\mathrm{m})$

Şekil 4: PPP ile kısa baz (ERBD) bağıl çözüm arasındaki farkların dağılım/frekans grafiği

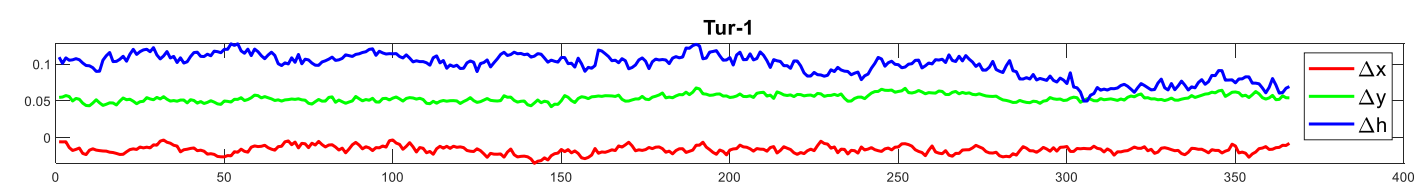

Tur-2

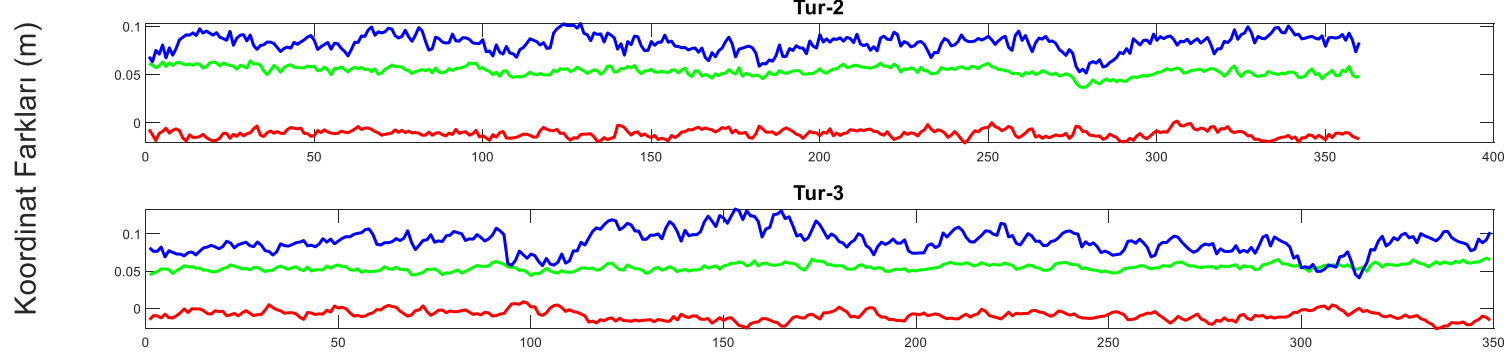

Tur-4

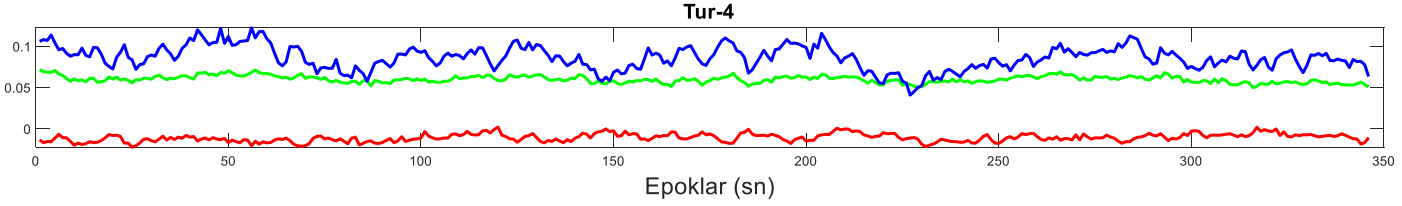

Şekil 5: PPP ile orta baz (ISTN) bağıl çözüm koordinat farkları

Orta baz (ISTN) bağıl çözüme göre alınan farklarda, $\Delta \mathrm{x}, \Delta \mathrm{y}$ ve $\Delta \mathrm{h}$ değerlerine ait KOH değerleri sırasıyla $\pm 0.0113 \mathrm{~m}$ ile $\pm 0.0173 \mathrm{~m} ; \pm 0.0540 \mathrm{~m}$ ile $\pm 0.0602 \mathrm{~m} ; \pm 0.0834 \mathrm{~m}$ ile $\pm 0.0995 \mathrm{~m}$ aralıklarında elde edilmiştir. Bu çözüm için de turlar arasında $\mathrm{KOH}$ değerlerine ait farklara bakıldığında, yatay koordinat bileşeni için mm seviyesi ve $\Delta \mathrm{h}$ için en büyük farkın $\mathrm{cm}$ seviyesinde $\left(\Delta \mathrm{x}_{\text {maks }}=0.0060 \mathrm{~m}\right.$ ve $\Delta \mathrm{x}_{\min }=0.0000 \mathrm{~m} ; \Delta \mathrm{y}_{\text {maks }}=0.0062 \mathrm{~m}$ ve $\Delta \mathrm{y}_{\min }=0.0001 \mathrm{~m} ; \Delta \mathrm{h}_{\text {maks }}=0.0161 \mathrm{~m}$ ve $\Delta \mathrm{h}_{\text {min }}=$ $0.0036 \mathrm{~m}$ ) olduğu görülmüştür. Farkların mutlak değerlerine bağlı hesaplanan $\mathrm{OMH}$ değerlerinin $\mathrm{KOH}$ değerlerine göre her turda ve her bileşen için bir miktar azaldığı görülmektedir.

Şekil 6'da verilen dağılım grafiğginde, çözümlerin farklarından elde edilen koordinat bileşenlerinin her turda Gauss normal dağ 1 lım eğrisine uyduğu ve Şekil 4’te elde edilen sonuçlara benzer bir durumun oluştuğu görülmektedir. 
Tablo 3: PPP ile orta baz (ISTN) bağıl çözüm arasındaki farklara ait istatistiksel sonuçlar

\begin{tabular}{|c|c|c|c|c|c|c|}
\hline & \multicolumn{3}{|c|}{ TUR-1 } & \multicolumn{3}{|c|}{ TUR-2 } \\
\hline & $\Delta \mathbf{x}(\mathbf{m})$ & $\Delta y(m)$ & $\Delta h(\mathrm{~m})$ & $\Delta \mathbf{x}(\mathbf{m})$ & $\Delta y(m)$ & $\Delta h(m)$ \\
\hline Ortalama & -0.0165 & 0.0539 & 0.0981 & -0.0110 & 0.0538 & 0.0829 \\
\hline Minimum & -0.0350 & 0.0420 & 0.0497 & -0.0209 & 0.0365 & 0.0516 \\
\hline Maksimum & -0.0032 & 0.0676 & 0.1276 & 0.0018 & 0.0643 & 0.1031 \\
\hline Aralık & 0.0318 & 0.0256 & 0.0779 & 0.0227 & 0.0278 & 0.0515 \\
\hline $\mathrm{KOH}$ & 0.0173 & 0.0541 & 0.0995 & 0.0118 & 0.0540 & 0.0834 \\
\hline \multirow[t]{3}{*}{$\mathrm{OMH}$} & 0.0165 & 0.0539 & 0.0981 & 0.0110 & 0.0538 & 0.0829 \\
\hline & \multicolumn{3}{|c|}{ TUR-3 } & \multicolumn{3}{|c|}{ TUR-4 } \\
\hline & $\Delta x(m)$ & $\Delta y(m)$ & $\Delta h(m)$ & $\Delta \mathbf{x}(\mathrm{m})$ & $\Delta y(m)$ & $\Delta h(m)$ \\
\hline Ortalama & -0.0092 & 0.0553 & 0.0896 & -0.0108 & 0.0600 & 0.0862 \\
\hline Minimum & -0.0271 & 0.0442 & 0.0410 & -0.0224 & 0.0500 & 0.0409 \\
\hline Maksimum & 0.0090 & 0.0676 & 0.1334 & 0.0021 & 0.0719 & 0.1226 \\
\hline Aralık & 0.0361 & 0.0234 & 0.0924 & 0.0245 & 0.0219 & 0.0817 \\
\hline $\mathrm{KOH}$ & 0.0113 & 0.0555 & 0.0910 & 0.0118 & 0.0602 & 0.0874 \\
\hline $\mathrm{OMH}$ & 0.0097 & 0.0553 & 0.0896 & 0.0108 & 0.0600 & 0.0862 \\
\hline
\end{tabular}
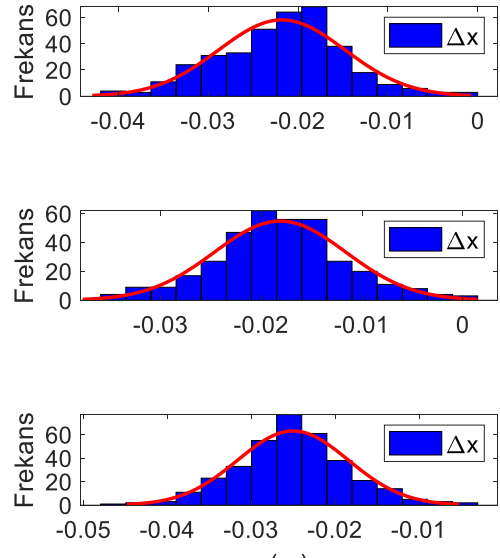

(m)

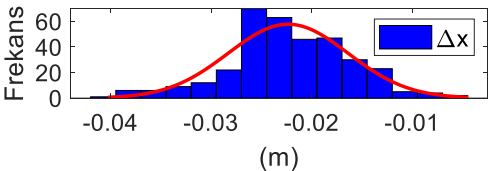

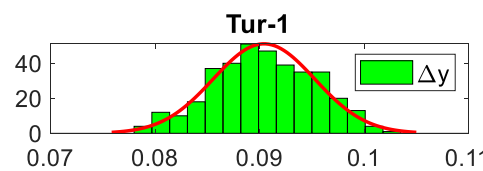
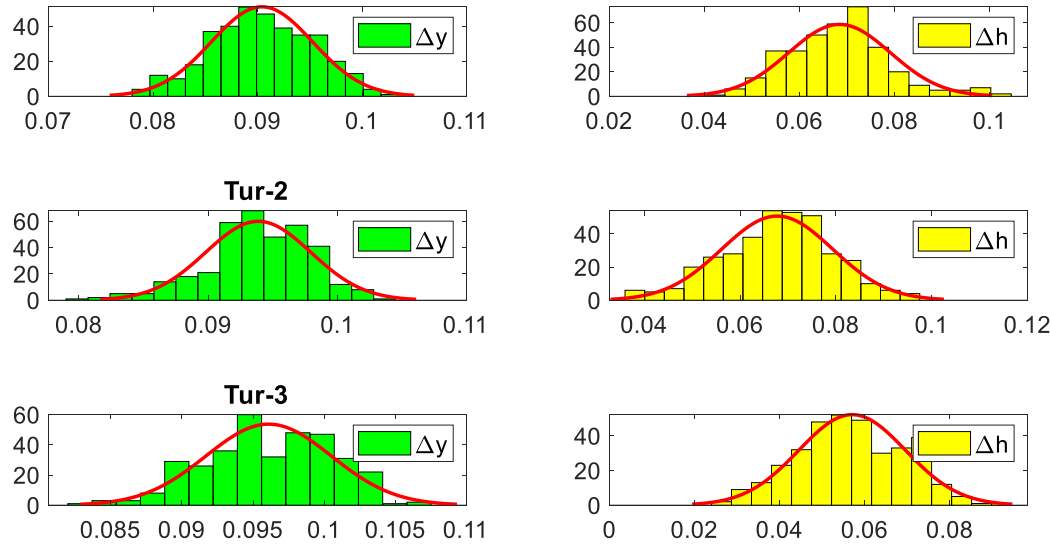

(m)

Tur-4

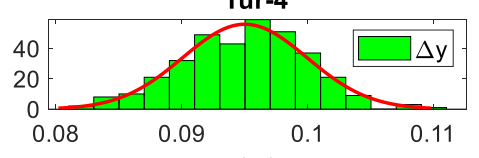

(m)

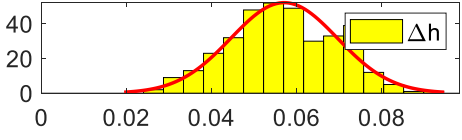

(m)

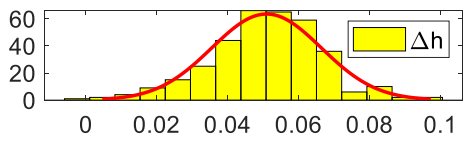

(m)

Şekil 6: PPP ile orta baz (ISTN) bağıl çözüm arasındaki farkların dağılım/frekans grafiği

PPP ile elde edilen kinematik veriye ait koordinat bileşenleri son çözüm stratejisi olan uzun baz (ISTA) bağıl çözüm ile elde edilen koordinat bileşenleri ile epok-epok karşılaştırılmış ve sonuçlar Şekil 7'de verilmiştir. Bu çözüme ait elde edilen koordinat farklarının istatistiksel bilgileri ise Tablo 4'te minimum ve maksimum KOH değerleri koyu renkte belirtilerek sunulmuştur. Uzun baz bağıl çözüme göre alınan farklarda, $\Delta \mathrm{x}, \Delta \mathrm{y}$ ve $\Delta \mathrm{h}$ değerlerine ait $\mathrm{KOH}$ değerleri sırasıyla $\pm 0.0046 \mathrm{~m}$ ile $\pm 0.0063 \mathrm{~m} ; \pm 0.0568 \mathrm{~m}$ ile $\pm 0.0661 \mathrm{~m} ; \pm 0.0605 \mathrm{~m}$ ile $\pm 0.0826 \mathrm{~m}$ aralıklarında elde edilmiştir. Burada, dört tur arasında oluşan altı farklı kombinasyona göre $\mathrm{KOH}$ değerleri arasındaki farklara bakıldığında, $\Delta \mathrm{x}$ ve $\Delta \mathrm{y}$ bileşenleri için mm seviyesinde bir değişim olduğu, $\Delta \mathrm{h}$ için ise en büyük farkın cm seviyesinde kaldığg $\left(\Delta \mathrm{x}_{\text {maks }}=0.0017 \mathrm{~m}\right.$ ve $\Delta \mathrm{x}_{\mathrm{min}}=0.0003 \mathrm{~m}$; $\Delta \mathrm{y}_{\text {maks }}=0.0093 \mathrm{~m}$ ve $\Delta \mathrm{y}_{\min }=0.0020 \mathrm{~m} ; \Delta \mathrm{h}_{\text {maks }}=0.0221 \mathrm{~m}$ ve $\Delta \mathrm{h}_{\min }=0.0040 \mathrm{~m}$ ) görülmüştür. Bu değerler, kısa süreli yürüyüş verisinde belirgin bir fark meydana getirmemekle birlikte farkların mutlak değerlerine bağlı hesaplanan OMH değerlerinin $\mathrm{KOH}$ değerlerine göre her turda ve her bileşen için bir miktar azaldığı bu çözümde de görülmektedir. 


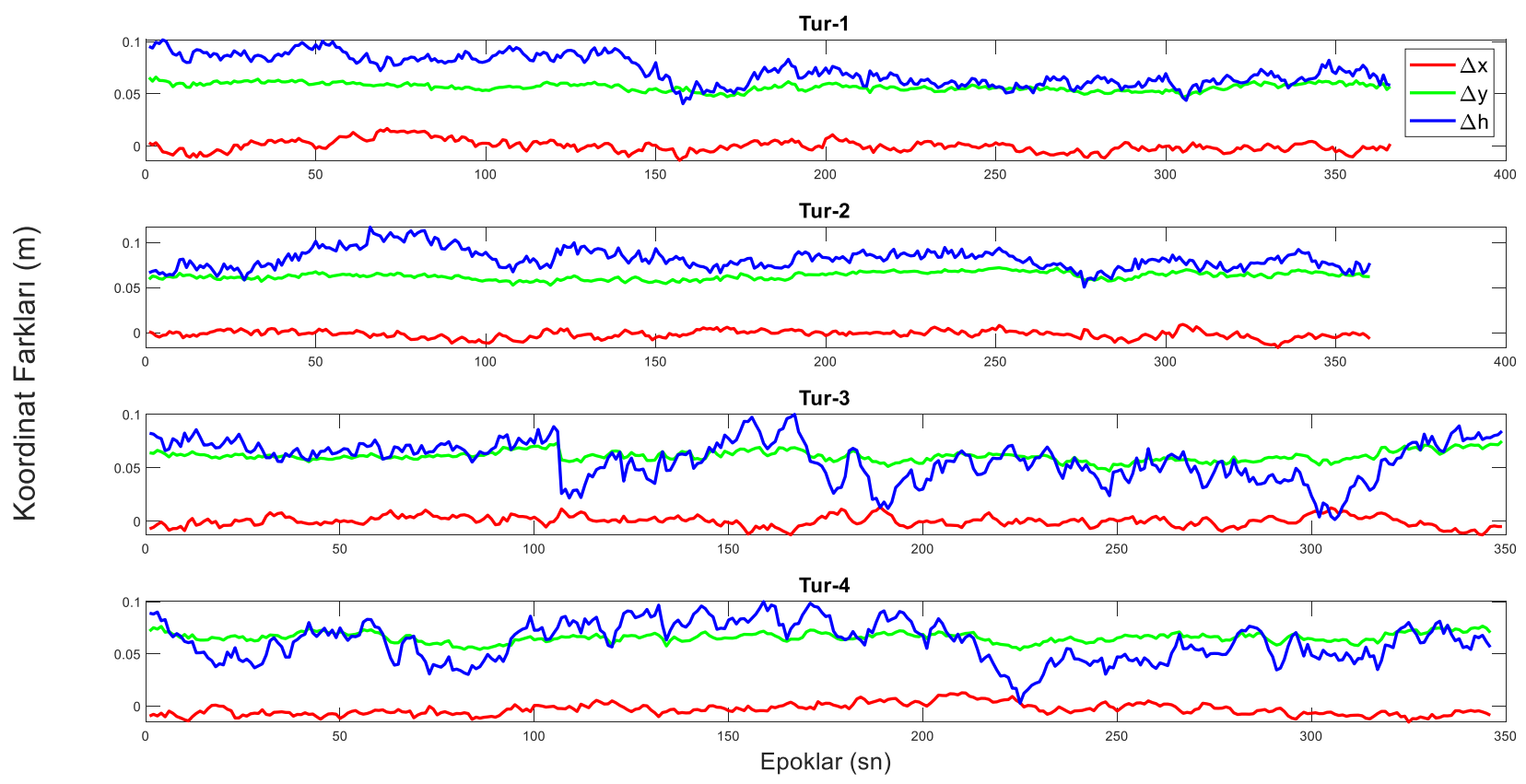

Şekil 7: PPP ile uzun baz (ISTA) bağıl çözüm koordinat farkları

Tablo 4: PPP ile uzun baz (ISTA) bağıl çözüm arasındaki farklara ait istatistiksel sonuçlar

\begin{tabular}{|c|c|c|c|c|c|c|}
\hline & \multicolumn{3}{|c|}{ TUR-1 } & \multicolumn{3}{|c|}{ TUR-2 } \\
\hline & $\Delta \mathbf{x}(\mathbf{m})$ & $\Delta y(m)$ & $\Delta \mathbf{h}(\mathbf{m})$ & $\Delta \mathbf{x}(\mathbf{m})$ & $\Delta y(m)$ & $\Delta h(\mathbf{m})$ \\
\hline Ortalama & 0.0002 & 0.0567 & 0.0727 & -0.0018 & 0.0631 & 0.0819 \\
\hline Minimum & -0.0136 & 0.0467 & 0.0406 & -0.0166 & 0.0527 & 0.0506 \\
\hline Maksimum & 0.0170 & 0.0662 & 0.1018 & 0.0092 & 0.0722 & 0.1173 \\
\hline Aralık & 0.0306 & 0.0195 & 0.0612 & 0.0258 & 0.0195 & 0.0667 \\
\hline $\mathrm{KOH}$ & 0.0056 & 0.0568 & 0.0740 & 0.0046 & 0.0633 & 0.0826 \\
\hline \multirow[t]{3}{*}{$\mathrm{OMH}$} & 0.0043 & 0.0567 & 0.0727 & 0.0036 & 0.0631 & 0.0819 \\
\hline & \multicolumn{3}{|c|}{ TUR-3 } & \multicolumn{3}{|c|}{ TUR-4 } \\
\hline & $\Delta \mathbf{x}(\mathbf{m})$ & $\Delta y(m)$ & $\Delta \mathrm{h}(\mathrm{m})$ & $\Delta x(m)$ & $\Delta y(m)$ & $\Delta h(m)$ \\
\hline Ortalama & 0.0002 & 0.0611 & 0.0576 & -0.0032 & 0.0660 & 0.0618 \\
\hline Minimum & -0.0127 & 0.0470 & 0.0016 & -0.0153 & 0.0539 & 0.0027 \\
\hline Maksimum & 0.0134 & 0.0750 & 0.1001 & 0.0128 & 0.0770 & 0.1002 \\
\hline Aralık & 0.0261 & 0.0280 & 0.0985 & 0.0281 & 0.0231 & 0.0975 \\
\hline $\mathrm{KOH}$ & 0.0049 & 0.0613 & 0.0605 & 0.0063 & 0.0661 & 0.0645 \\
\hline $\mathrm{OMH}$ & 0.0039 & 0.0611 & 0.0576 & 0.0053 & 0.0660 & 0.0618 \\
\hline
\end{tabular}

Son olarak, Şekil 8'de uzun baz (ISTA) bağıl çözümü ile PPP yöntemi ile hesaplanan koordinat değerlerinin birbirinden epok-epok çıkarılması ile elde edilen farklara ait dağılım grafiği verilmiştir. Koordinat farkları sıfır değerine kısa ve orta baz çözümlerine göre daha iyi yakınsamıştır. Bu durum uzun baz çözümleri ile kinematik PPP çözümlerinin yakın sonuçlar verdiğini göstermektedir.

\section{Sonuçlar ve Değerlendirme}

Gerçekleştirilen bu çalışmada GNSS ölçme süresinin azaldığı durumlarda, kısa süreli kinematik GPS+GLONASS gözlemlerinin PPP yöntemi kullanılarak elde edilen 3 boyutlu koordinatlarının kısa, orta ve uzun baz mesafelerine dayalı bağıl konum belirleme çözümlerinden elde edilen koordinat değerlerine hangi oranda ulaşabileceği yapılan tekrarlı turlar ile incelenmiştir. Bilindiği gibi GNSS literatüründe bağıl konum belirleme çözümlerinde baz uzunluğu arttıkça konum doğruluğu düşmektedir. Buna göre yapılan çalışmada, en iyi konumlama değerlerinin kısa baz bağıl çözümünden geleceği 
dikkate alındığında epok-epok elde edilen PPP çözümlerinin en kısa baz (ERBD) çözümünden farklarının alınması ile elde edilen $\Delta \mathrm{x}, \Delta \mathrm{y}$ ve $\Delta \mathrm{h}$ bileşenleri en büyük farkları oluşturmuştur. Bağıl çözümde baz uzunluğu arttıkça çözüm hatası da artacağından dolayı, orta ve uzun baz bağıl çözümler ile karşılaştırılan PPP çözümünde farkların azalması anlamlıdır. Bu durumda, sırasıyla PPP çözümlerinin orta baz (ISTN) ve sonrasında uzun baz (ISTA) ile olan bağıl konum çözüm farkları daha da azalmıştır. PPP çözümleri en fazla ve yaklaşık değer olarak uzun baz (ISTA) bağıl konum koordinat çözümlerine yakınsamakla birlikte, genel olarak ITRF2014 datumu ölçü epoğunda yapılan tüm çözümler arasındaki farklar birbirine cm seviyesinin altında yakınsamıştır.
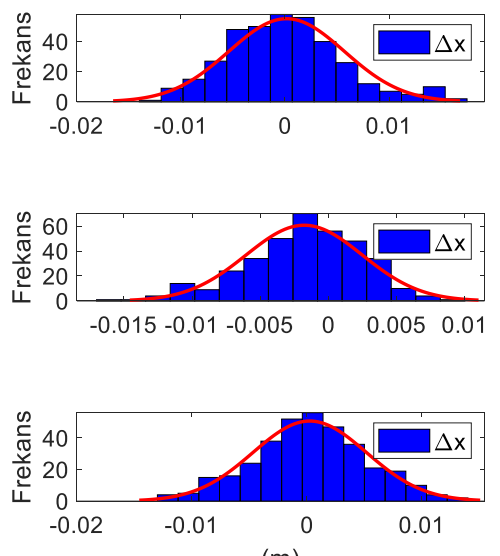

(m)

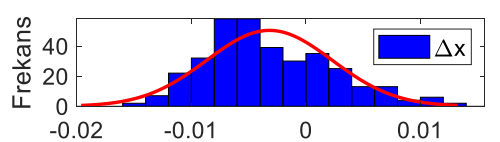

$(\mathrm{m})$
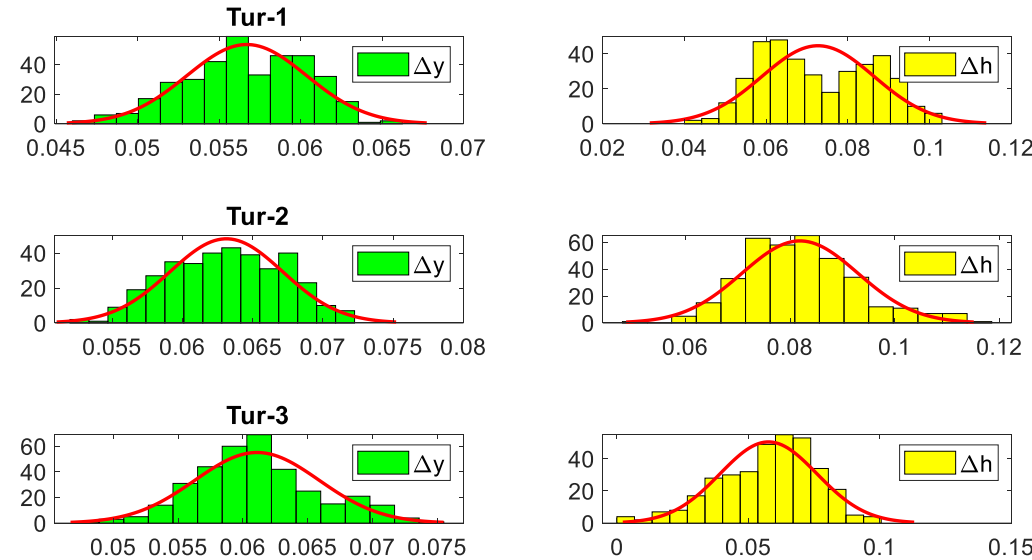

(m)

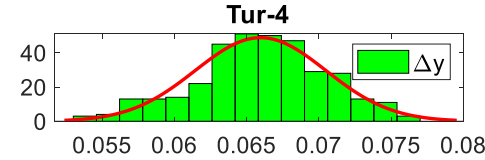

$(\mathrm{m})$

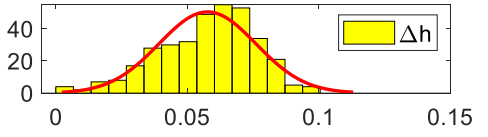

(m)

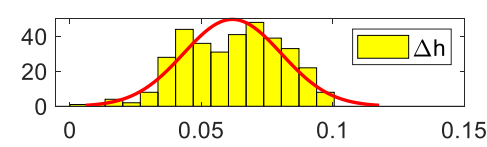

$(\mathrm{m})$

Şekil 8: PPP ile uzun baz (ISTA) bağıl çözüm arasındaki farkların dağılım/frekans grafiği

Çalışmada koordinat farkları için elde edilen $\mathrm{KOH}$ ve $\mathrm{OMH}$ değerleri (Tablo 2-3-4) incelendiğinde $\Delta \mathrm{y}$ değerinin $\Delta \mathrm{x}$ değerine göre daha büyük olduğu ve $\Delta x$ değerinde elde edilen düşüşün bu bileşende olmadığı görülmüştür. Bu durum, $\Delta y$ değeri için orta ve uzun bazlarda daha stabil çözümlerin elde edildiğini göstermektedir. Yükseklik bileşeni $\Delta$ h için kısa baz fark değerleri ile karşılaştırma yapıldığında $\mathrm{KOH}$ değerlerinin orta ve uzun baz çözümleri için arttığı görülmektedir. Yine Tablo 2-3-4 incelendiğinde, kısa baz (ERBD) bağıl çözüm için alınan farklara ait $\mathrm{KOH}$ değerlerinin, $\Delta \mathrm{x}$ bileşeni için $\Delta \mathrm{y}$ ve $\Delta \mathrm{h}$ bileşenlerine ait $\mathrm{KOH}$ değerlerinden küçük olduğu, bu durumun orta baz (ISTN) ve uzun baz (ISTA) bağıl çözümleri için de korunduğu ve bununla birlikte fark değerlerinin yaklaşık aynı oranda azaldığı görülmektedir. Bununla birlikte, Şekil 4-6-8'de farklara ait dağılım grafikleri, farkların beklenen değerinin sıfır olma durumuna göre incelendiğinde, bu durumun her turda ve üç bileşen için uzun baz (ISTA) bağıl çözümünden (Şekil 8) elde edilen farklarda daha belirgin şekilde ortaya çıktığı görülmektedir. Şekil 8'de dağılım grafikleri incelendiğinde $\Delta x$ değerinin Gauss normal dağılımına diğer çözümlerden daha iyi uyduğu ve beklenen değerin sıfıra yaklaştığı görülmektedir. Bu çözüme ait koordinat bileşenlerinin diğer çözümlerden daha fazla sıfıra yaklaştığı görülmektedir. Ayrıca, farkların mutlak değerlerine bağlı hesaplanan $\mathrm{OMH}$ değerlerinin $\mathrm{KOH}$ değerlerine göre her turda ve her bileşen için bir miktar düştüğü görülmektedir. Her ne kadar, $\mathrm{KOH}$ ve OMH değerleri, fark değerlerinin işaretinden bağımsız olsa da her ikisinde düşük değerlerin elde edilmesi, sırasıyla modelin prezisyonu ve doğruluğunu göstermesi açısından önemlidir. Tüm sonuçlar kısa süreli kinematik GPS+GLONASS gözlemleri için PPP yönteminin etkin biçimde tüm bağıl konum belirleme çözümlerine koordinat değerleri için cm doğrulukta yakınsadığını göstermektedir. Bu bulgular kara, deniz ve hava gibi farklı platformlarda yapılacak kısa ölçü süresine sahip GNSS uygulamalarında, PPP yönteminin kullanım potansiyelinin bağıl konum belirlemeye göre önemli derecede artacağını göstermektedir. Yakın bir gelecekte etkin olarak kullanılacak PPP-AR algoritma çözümleri ile bu gelişimin daha da artacağı düşünülmektedir. 


\section{Teşekkür}

ISTN ve ISTA sabit GNSS referans istasyonu veri katkılarından ötürü TKGM ve IGS'ye, CSRS-PPP yazılım desteğinden ötürü NRCan'a teşekkür ederim.

\section{Kaynaklar}

Alkan, R. M., \& Öcalan, T. (2013). Usability of the GPS precise point positioning technique in marine applications. The Journal of Navigation, 66(4), 579-588.

Alkan, R. M., Saka, M. H., Ozulu, İ. M., \& İlçi, V. (2017). Kinematic precise point positioning using GPS and GLONASS measurements in marine environments. Measurement, 109, 36-43.

Bezcioğlu, M., Yiğit, C. Ö., \& Bodur, M. N. (2019). Kinematik PPP-AR ve Geleneksel PPP Yöntemlerin Performanslarının Değerlendirilmesi: Antarktika Yarımadası Örneği. Afyon Kocatepe Üniversitesi Fen Ve Mühendislik Bilimleri Dergisi, 19(1), $162-169$.

Bisnath, S., \& Gao, Y. (2008). Current state of precise point positioning and future prospects and limitations. Observing our changing earth, 615-623. Springer, Berlin.

Chen, K., \& Gao, Y. (2005). Real-time precise point positioning using single frequency data. Proceedings of ION GNSS, 1514-1523.

Choy, S., \& Harima, K. (2019). Satellite delivery of high-accuracy GNSS precise point positioning service: an overview for Australia. Journal of Spatial Science, 64(2), 197-208.

El-Mowafy, A. (2011). Analysis of web-based GNSS post-processing services for static and kinematic positioning using short data spans. Survey review, 43(323), 535-549.

Erdoğan, B., Karlıtepe, F., Öcalan, T., \& Tunalığlu, N. (2018). Performance analysis of Real Time PPP for transit of Mercury. Measurement, 129, 358-367.

Geng, J., Teferle, F. N., Meng, X., \& Dodson, A. H. (2010). Kinematic precise point positioning at remote marine platforms. GPS solutions, 14(4), 343-350.

Grayson, B., Penna, N. T., Mills, J. P., \& Grant, D. S. (2018). GPS precise point positioning for UAV photogrammetry. The Photogrammetric Record, 33(164), 427-447.

Gross, J. N., Watson, R. M., D’Urso, S., \& Gu, Y. (2016). Flight-test evaluation of kinematic precise point positioning of small UAVs. International Journal of Aerospace Engineering, 2016 id 1259893.

Héroux, P., Gao, Y., Kouba, J., Lahaye, F., Mireault, Y., Collins, P., Tètreault, P., \& Chen, K. (2004). Products and applications for Precise Point Positioning-Moving towards real-time. Proceedings of ION GNSS, 1832-1843.

Li, X., Ge, M., Zhang, H., \& Wickert, J. (2013). A method for improving uncalibrated phase delay estimation and ambiguity-fixing in realtime precise point positioning. Journal of Geodesy, 87(5), 405-416.

Lipatnikov, L.A., \& Shevchuk, S.O. (2019), Cost Effective Precise Positioning with GNSS, The International Federation of Surveyors (FIG), No: 74.

Öcalan, T., Erdoğan, B., Tunalığlu, N., \& Durdağ, U.M. (2016). Accuracy Investigation of PPP Method Versus Relative Positioning Using Different Satellite Ephemerides Products Near/Under Forest Environment. Earth Sciences Research Journal, 20(4), D1-D9.

Robustelli, U., Baiocchi, V., \& Pugliano, G. (2019). Assessment of dual frequency GNSS observations from a Xiaomi Mi 8 Android smartphone and positioning performance analysis. Electronics, 8(1), 91.

Wübbena, G., Schmitz, M., \& Bagge, A. (2005). PPP-RTK: precise point positioning using state-space representation in RTK networks. Proceedings of ION GNSS ,5 13-16.

Xu, P., Shi, C., Fang, R., Liu, J., Niu, X., Zhang, Q., \& Yanagidani, T. (2013). High-rate precise point positioning (PPP) to measure seismic wave motions: an experimental comparison of GPS PPP with inertial measurement units. Journal of Geodesy, 87(4), 361-372.

Yiğit, C. Ö. (2016). Experimental assessment of post-processed kinematic Precise Point Positioning method for structural health monitoring. Geomatics, natural hazards and risk, 7(1), 360-383.

Zumberge, J. F., Heflin, M. B., Jefferson, D. C., Watkins, M. M., \& Webb, F. H. (1997). Precise point positioning for the efficient and robust analysis of GPS data from large networks. Journal of geophysical research: solid earth, 102(B3), 5005-5017.

URL-1: https://webapp.geod.nrcan.gc.ca/geod/tools-outils/documentation.php, (Erişim Tarihi: 2 Mayıs 2020). 